\title{
Relevance of Use of Decorative and Applied Art Techniques in Collections of Footwear and Accessories
}

\author{
Elena S. RYKOVA \\ Ph.D. (in Technical Sciences) \\ Associate Professor \\ Department of Artistic Modeling, Design and Technology of Leather Products \\ Technological Institute of Textile Industry \\ Russian State University named after A.N. Kosygin (Technology. Design. Art) \\ 33, Sadovnicheskaya Str., building 1, Moscow, 117997, Russia \\ elena-mgudt@mail.ru \\ Anna A. FOKINA \\ Ph.D. (in Technical Sciences) \\ Associate Professor \\ Department of Artistic Modeling, Design and Technology of Leather Products \\ Technological Institute of Textile Industry \\ Russian State University named after A.N. Kosygin (Technology. Design. Art) \\ 33, Sadovnicheskaya Str., building 1, Moscow, 117997, Russia \\ anna-mgudt@mail.ru \\ Olga A. BELITSKAYA \\ Ph.D. (in Technical Sciences) \\ Associate Professor \\ Department of Artistic Modeling, Design and Technology of Leather Products \\ Technological Institute of Textile Industry \\ Russian State University named after A.N. Kosygin (Technology. Design. Art) \\ 33, Sadovnicheskaya Str., building 1, Moscow, 117997, Russia \\ okotl@mail.ru
}

\begin{abstract}
Modern fashion returns to the traditions of our ancestors, more and more consumers give their preference to stylish hand-made accessories. Under the influence of various ethnic cultures and as a result of globalization, there is a rethinking of national traditions while maintaining the existing cultural priorities of Russia. Many designers include in their collections shoes, bags, accessories made in various techniques of leather processing. Artistic processing of leather is decorating clothes, shoes, leather goods, drawing or embossing both natural and artificial leather. The article establishes the relevance of the use of arts and crafts techniques in modern fashion, systematizes the material on the techniques of working with leather, considers the technology of making collections of shoes and accessories using hand-painted and leather embossing techniques, assesses the prospects of the collections. The process of introducing the techniques of painting and embossing leather into the educational process of the Department of Artistic Modeling, Design and Technology of Leather Products of the Russian State University named after Kosygin is presented., on the example of the collections "Own Territory", designer Mochalina and "The Future of the Past" designer Polishchuk.
\end{abstract}

Keywords: fashion industry; art painting; leather; footwear; accessories. 


\section{Introduction}

The process of globalization is causing great interest in arts and crafts. The artistic heritage in all its diversity organically enriches new decorative forms caused by the wide penetration of technologies of the 21 st century. Under the influence of various ethnic cultures and as a result of globalization, there is a rethinking of national traditions while maintaining the existing cultural priorities of Russia. Nowadays, designers are increasingly turning to folk art to solve artistic problems. It enriches designers in a creative way, helps to increase their emotional charge, artistic processing and techniques for working with leather are of great interest. The beginning of artistic processing of leather can be safely attributed to the Stone Age: even then there were clothes made of skins and the first, so-called, accessories - belts, belts and bags. In the VIII-XII centuries, leather products became so popular that even wallpaper in the houses of noble people began to be made of leather. There were many ways of processing this natural material in ancient times: they used embossing, weaving, perforation. One of the most popular was the engraving technique, where acrylic paints were used, which are still used today.

\section{Literature Review}

Leather production developed tirelessly: handicraft gradually began to be replaced by industrial production of leather goods (Jacome, Glyn, 2016; Vass, Monlar, 2017). However, the painstaking work of a person on each thing has always been and continues to be incredibly in demand (Mochalina, Rykova, Fokina, 2019).

Table 1. Techniques of artistic processing of leather (fragment, photo from the archive of the Department AMDTLP of the RSU named after Kosygin)

\begin{tabular}{|c|c|c|}
\hline $\begin{array}{c}\text { Technique of } \\
\text { artistic processing } \\
\text { of leather }\end{array}$ & Performance characteristics of the technique & $\begin{array}{l}\text { Image - an example of } \\
\text { implementation in the product } \\
\text { (photo from the archive of the } \\
\text { Department of Artistic Modeling, } \\
\text { Design and Technology of Leather } \\
\text { Products of the Russian State } \\
\text { University named after A.N. } \\
\text { Kosygin) (AMDTLP of the RSU } \\
\text { named after A.N. Kosygin) }\end{array}$ \\
\hline
\end{tabular}

\begin{tabular}{cl}
\hline $\begin{array}{c}\text { Embossing with } \\
\text { filling }\end{array}$ & $\begin{array}{l}\text { Cutting out elements of the future relief from cardboard } \\
\text { or pieces of blinders and placing them under a layer of } \\
\text { pre-moistened skin, then the skin is pushed through to } \\
\text { reveal the relief. When dry, it hardens and "remembers" } \\
\text { the embossed decor. }\end{array}$
\end{tabular}

Perforation With the help of tools of various shapes, perforations are carved in the leather, arranged in the form of an ornament. This technique is also used to create complex compositions like a stained-glass window or arabesque.

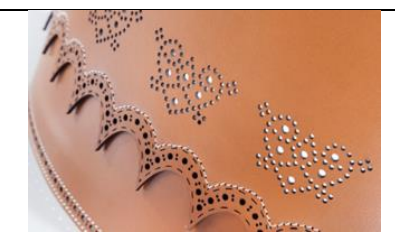

Pyrography The drawing is applied to the surface using a hot needle. In the classical form, pyrography was done using heated copper strains; in the modern form, a pyrograph is used. With the help of pyrography, very delicate and complex patterns can be applied to the skin. 


\begin{tabular}{ll}
\hline $\begin{array}{l}\text { Painting with } \\
\text { paints }\end{array}$ & $\begin{array}{l}\text { Drawing patterns with paint on the surface of leather } \\
\text { products. This technique for natural leather allows you to } \\
\text { significantly diversify the design options for new } \\
\text { products. }\end{array}$
\end{tabular}

Modern fashion returns to the traditions of our ancestors, more and more consumers give their preference to stylish hand-painted accessories (Falko, Kravtsova, Lukasheva, 2018). The use of various techniques for working with leather and the use of arts and crafts in the context of modern fashion is gaining popularity in the fashion industry (Acharya, Singh, Pereira, Singh, 2018; D'Avolio, Bandinelli, Rinaldi, 2015). Designers and fashion houses include in their collections shoes, bags, accessories with various techniques of leather processing (Polishchuk, Rykova, 2019).

Materials and methods. Artistic processing is decorating clothes, shoes, leather goods, drawing a pattern is possible, both on natural and artificial leather (Polishchuk, Rykova, 2019). In Table 1, we have systematized the material on the most popular techniques for working with leather. Painting with paints is one of the most common techniques; the decoration of genuine leather products can be done in various ways.

When using the stencil technique for applying images, the required stencils are cut out of thin plastic, cardboard or paper. Drawings obtained using various natural stencils, for example, leaves of some plants with a complex carved shape, can look very impressive.

When applying complex images to the surface of natural leather, the technique of hot batik is often used. Its essence lies in the fact that first a piece of an ordinary wax candle is melted in a water bath, and then the resulting liquid hot composition is applied with a brush to those places where the skin should not be painted. After applying the wax, the leather is covered with paint.

There are other interesting techniques, such as the bitmap method. The essence of the technique is that mixing shades and achieving the desired effect occurs from a certain distance, and the beauty and grace of painstaking work is revealed close by. The technique resembles pointillism - a stylistic trend in painting.

Airbrushing is a fine art technique that uses an airbrush as a tool to apply liquid or powder dye using compressed air to a surface. The airbrush will allow you to apply the thinnest layers, as well as make color stretches, color transitions and gradients.

Painting on natural leather can also be done according to the classical technology - painting with a brush, using a pencil, a brush and penetrating dyes (as an option, surface acrylic paints) (Mochalina et al., 2019). The advantage of this technology is the uniqueness of each pattern. Paints for painting on leather are colored opaque acrylic dyes, elastic, non-cracking and non-crumbling. They can dye natural leather, artificial and vinyl. The most popular brands of paints for leather products: Saphir, Salamander, Leather Studio Plaid, Acrylic Paint PBO Deco, Tair.

Painting on fabrics and leather has existed for more than 10 centuries, but interest in this type of art has not faded away, therefore, in the educational process of the Department of Artistic Modeling, Design and Technology of Leather Products (KMK and TIK), technologies of artistic leather processing are used for creating collections of shoes and accessories. The first step in creating a student shoe collection is often working with a creative source that shapes the image of future products. The success of the collection depends on this stage, the designer should quite consciously turn to the objects and phenomena of the surrounding reality, it is necessary to constantly observe and study the artistic heritage, analyze and select the source material for further creative work. 
Anything that can be transformed, associatively transformed into shoes or accessories can be selected as a creative source: natural phenomena, events of public life, works of art of literature and art, choreography, works of architecture, engineering structures, objects of material culture and decorative and applied arts, forms of living nature (bionics) (Rykova, Medvedeva, 2019). A creative approach to transforming the original source - not copying it, but associative rethinking - gives an endless wealth of ideas. The creative method of working on new models of shoes and accessories, assuming the presence of a source, seems to be the most promising: when creating new forms of shoes, it is necessary to proceed, first of all, from the main idea that prompted creativity, the expression of an idea can be not only a visually perceived material form, but also be in the nature of abstract concepts (Brito, Soares, Almeida, Monte, Byvoet, 2015; Lee, Jirousek, 2015).

Fashion designers often find ideas for new collections in other areas of art. The following areas of art had a strong influence on the development of fashion:

- Constructivism (highlighting the design and technical side of a work of art);

- Cubism (an attempt to depict an object from all sides simultaneously, as a combination of geometric shapes);

- Surrealism (paradoxical, unexpected connection of seemingly incompatible, reflection of the stream of consciousness without control from the mind);

- Pop art (inclusion of photographs, reproductions and illustrations in the composition of real objects);

- Postmodernism (the use of previously created forms to build a new one, the search for new relationships between styles);

- Op-art (the use of various visual illusions, which are achieved by sharp color contrasts, intersections of winding lines) (Mochalina, Rykova, Fokina, 2018).

The selection of colors also plays an important role in the creation of a collection. Optimal color ratio: base color $60 \%$; additional $30 \%$; accentuating $10 \%$.

Let us consider the features of creating collections using various techniques of decorative and applied art on the example of the collection "Own Territory" by Mochalina. The creative source for creating a collection is the direction in art of the late 50s - early 60s. - "pop Art". Advertising, style icons, mass media and, of course, fashion played a leading role in the development of the direction (Quinn, 2010). The most striking example of the manifestation of pop art in clothing design is the Modrian Look line, created by Yves Saint Laurent in 1965 (Falko et al., 2018). The dress, created by the great French couturier, based on the works of the artist Piet Modrian, is one of the symbols of the 60s era (Fig. 1).

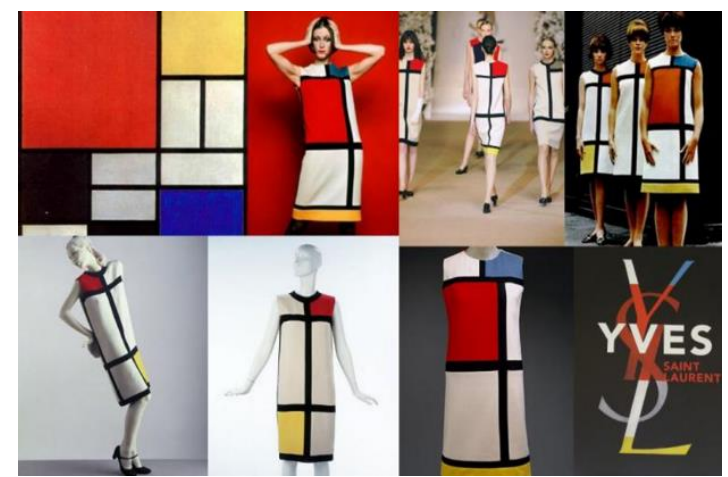

Figure 1. The Modrian Look collection of Yves Saint Laurent, 1965

Pop art clothing is a crazy cocktail of colors, unusual and catchy shapes, as well as synthetic fabrics. One of the brands producing collections in the style of pop art is an Italian brand specializing in the production of men's, women's and children's clothing, footwear, accessories and perfumery Moschino. Moschino's philosophy is an ironic attitude to fashion: the brand's collections are 
decorated with prints in the form of logos of famous brands, cartoon characters, food products, and playful inscriptions. Elegant outfits Franco Moschino complemented with provocative inscriptions, used pop art images. Moschino Couture collections were a reflection of social and political aspects (Almond, 2010; Brito et al., 2015).

The current fashion trend today is clothing completely covered with pop art prints or with one image that effectively contrasts against a plain background. Moreover, it can be a tight cloak of a strict classic cut, and a light straight sleeveless T-shirt dress. Pop art can be traced to the collections of Marni, Dolce \& Gabbana and others. Balenciaga has transformed casino attributes into intricate designs. And in the collection of Mary Katranzu, dedicated to the 10th anniversary of the brand, dresses with the print of dozens of images of classical and modern art were presented (Fig. 2).

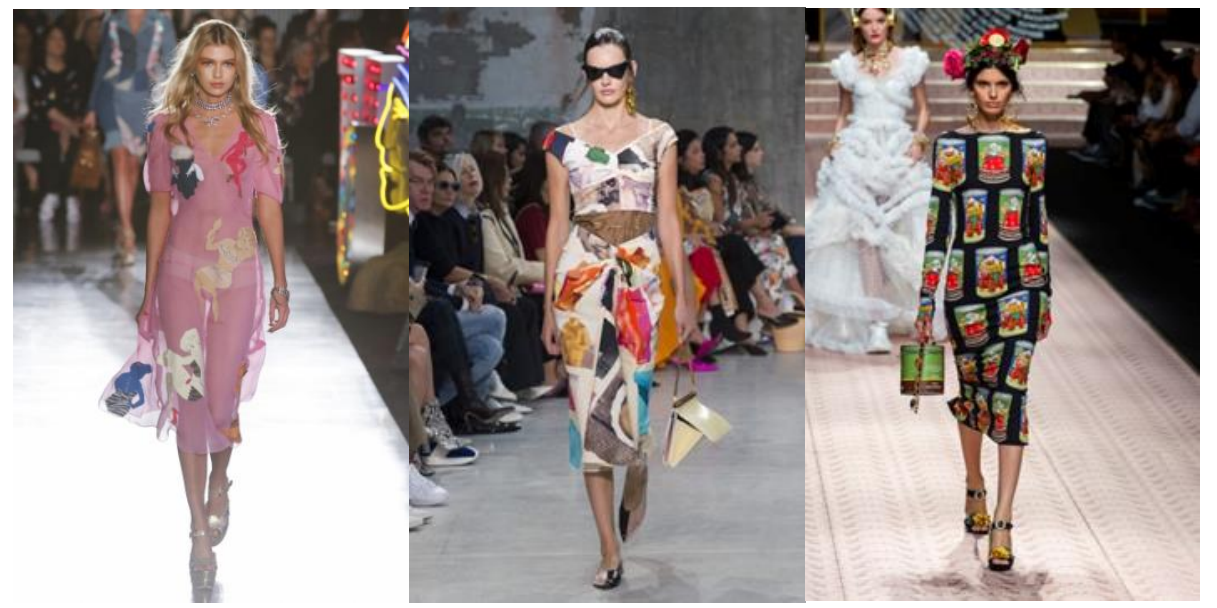

Figure 2. Collections in the style of «pop art» (Pop art style in clothes)

The creative source for the creation of the collection "Own Territory" is the direction in the art of the late 50s - early 60s. - "pop art" - the work of Roy Lichtenstein (Falko et al., 2018) (Fig. 3).

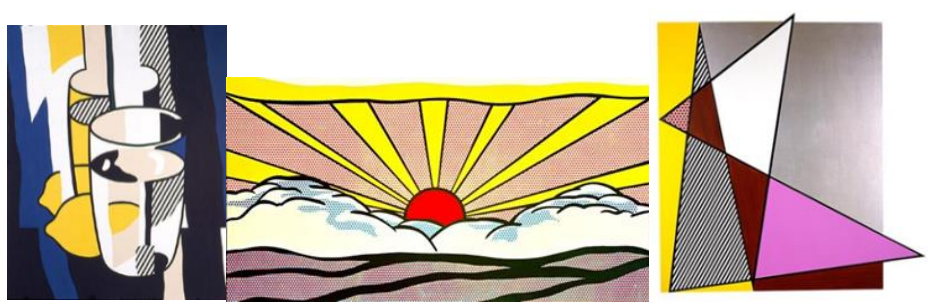

\section{Figure 3. Paintings by Roy Lichtenstein "Glass and Lemon in the Mirror", "Sunrise", "Imperfect Picture" (from left to right)}

On the basis of the creative source "pop art", sketches of the collection, presented in the figure, have been developed. At the first stage, sketches were made and the main elements of the artist's work were highlighted. The second stage of the sketch design of the collection is the execution of a series of fore-sketches based on several shoe designs and the stylization of the fragments of the paintings, the change in the drawing taking into account the constructive lines of the models. The third stage of the draft design is the selection of the most successful fore-sketches and the creation of several variants of shoe models with different color schemes.

The result of the sketch design was a series of five sketches of the collection "Own Territory", these are models of boots with various patterns in the style of «pop art» on the ankle boots. Each model is decorated according to the draft design using techniques: applique, intarsia, painting with paints. Several models of the collection are decorated in the process of assembling the blanks of the shoe 
upper, in the rest the decoration was carried out using the painting technique with paints at the stage of finishing, after assembling the shoes (Fig. 4).

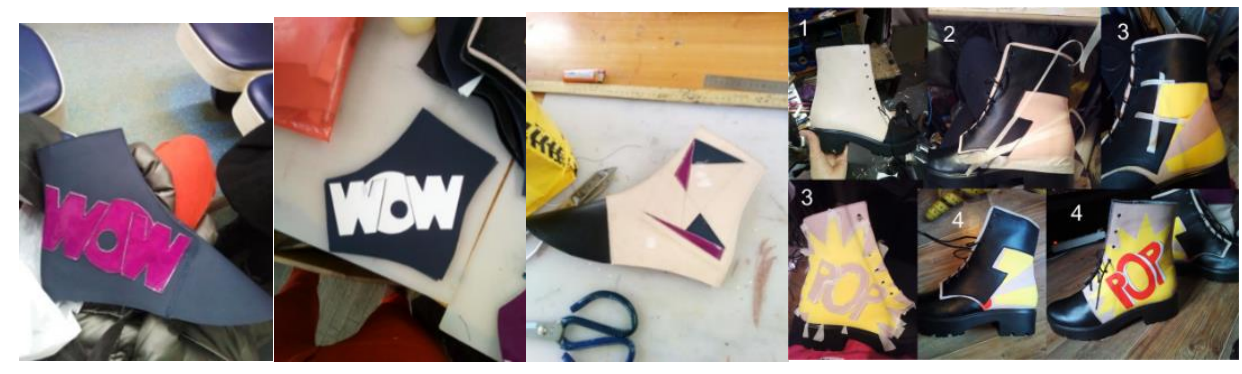

Figure 4. Decorating models of the collection «Own Territory» author Mochalina (archive of the department of AMDTLP of the RSU named after Kosygin)

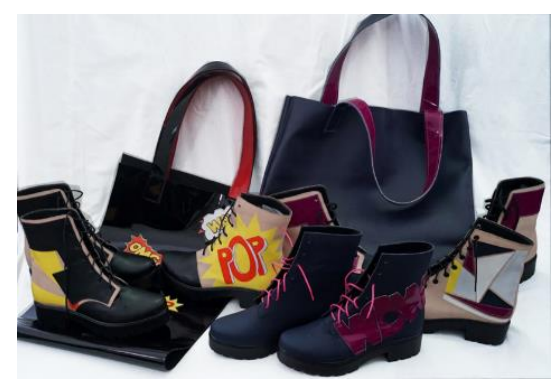

Figure 5. Collection of footwear and accessories «Own territory» author Mochalina, head Rykova (archive of the department AMDTLP of the RSU named after Kosygin)

The technique of arts and crafts - leather embossing, is no less interesting for teaching students and is also introduced in the educational process of the department of AMDTLP of the RSU named after Kosygin when creating collections of shoes and accessories.

Leather embossing, as an artistic technique, reached its zenith in the Iberian Peninsula between the 15th and 18th centuries. Gradually, this technique spread throughout Europe and Latin America, even reaching Japan. The method of making embossed leather and the methods of its use have come down to us thanks to old paintings and literature. Initially, embossing was an artistic technique in which the front side of the leather was covered with metal (gold or silver) foil, in order to subsequently apply embossing, multi-color patterns to the leather and lacquer it. The gilded leather was cut into rectangles of approximately the same size, which were sewn together to obtain a panel of the required size. The first mentions of the term - embossing, belong to the XII-XIII centuries, and the oldest objects that have come down to us - to the XV century. However, the gilding of leather, which is the basis of embossing, has been known since ancient times, it was known about it in Ancient Egypt, Rome and Byzantium, mentions of it can be found in documents and literary works of those times. In the few medieval manuals on various crafts that have survived to this day, they concisely describe the technique of gilding leather. Preserved leather bindings with gold interspersed dating back to the 8th or 9th centuries. Beginning in the 12th century, in Eastern Europe, gilded leather was used to sew clothes, shoes, belts, as well as headdresses for scientists and clergy. In the ancient archives of the Spanish kings, references to embossed leather dating back to the XIV century have been found. Various pillows, cases, all kinds of decorations for the altar and other items of church use were made of it, they draped walls with it, luxurious canopies, curtains, bedspreads and tablecloths were made from it.

In the documents of the late 15th century, masters who masterfully master the technique of embossing and their products are often mentioned. Starting from the first third of the 16th century, the rules of this craft were introduced in the craft workshops of many cities. Thanks to this, descriptions of the embossing technique, raw materials and tools used by the masters, and even 
some of the patterns with which they decorated their products, have been preserved. Also known are the cities that were at that time the centers of the production of embossed leather, such as Seville, Granada, Cordoba, Valencia, Valladolid, Barcelona and Madrid, and the names of some masters (Polishchuk, Rykova, 2019).

In order to develop art education in the educational process of the Department of Artistic Modeling, Design and Technology of Leather Products, Russian State University named after Kosygin used the development of the authors of the article - scientific and informational material "The use of various materials and decorating techniques in the collections of shoes and accessories" (Fig. 6), which was used to decorate the collection of shoes and accessories. "The Future of the Past" is a collection of modernized clothes, footwear and accessories in the militarized ethnic style, made using the leather embossing technique.

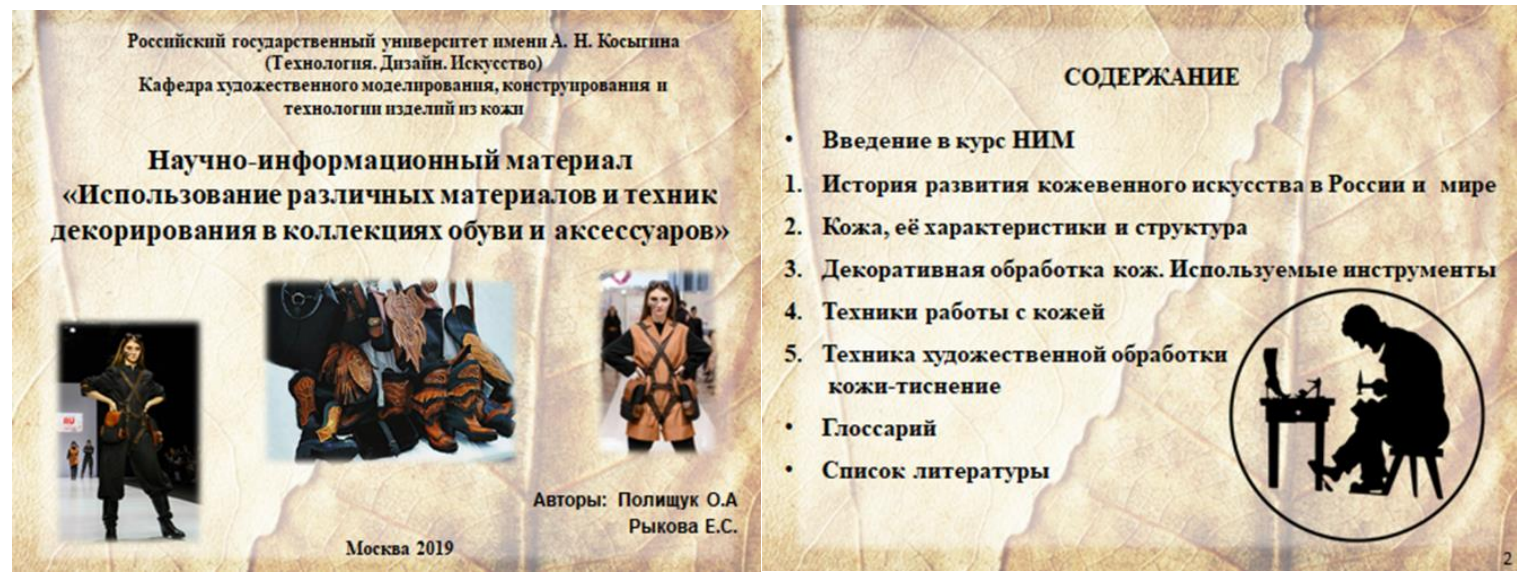

Figure 6. Fragment of the scientific and informational material «The use of various materials and decorating techniques in the collections of shoes and accessories», authors Polishchuk, (archive of the Department of AMDTLP of the RSU named after Kosygin)

The collection reflects the current problems of social life. The idea of the collection is to show a society shrouded in anger, resentment, envy, insecurity, aggression and life on the brink of war. The collection seeks to draw attention to people's aggression, to show that war leaves its mark everywhere: it is reflected as an indelible stain in the memory of its participants and their families, passes through the memory of generations, is reflected in art and creativity. Collections students want to draw attention to this terrible and still relevant topic, all creative people - "FOR PEACE", the main message of the collection: "Remember that there is no war" (Fig. 7).
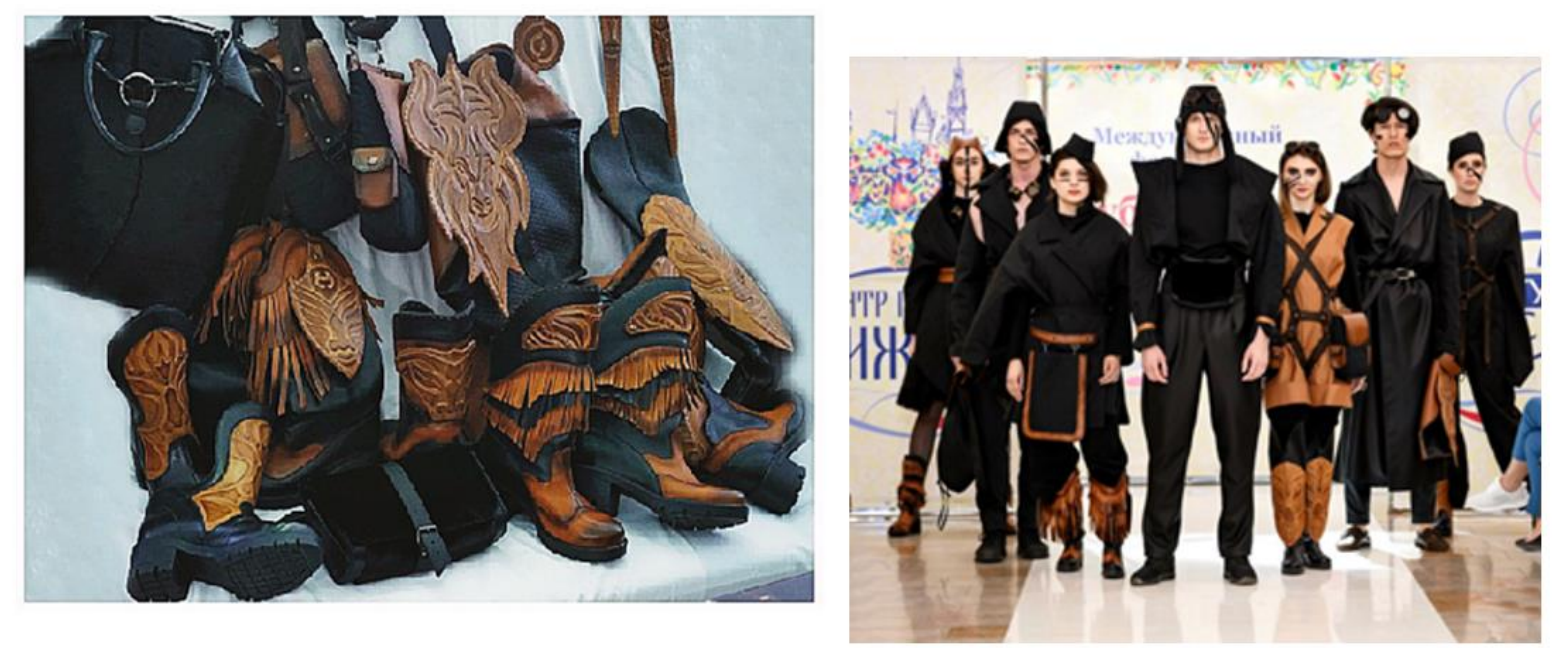

Figure 7. Collection "Future of the past", author Olga Polishchuk RSU n.a. Kosygin, the head is Rykova (archive of the department of AMDTLP of the RSU named after Kosygin) 
The collection "Future of the Past" consists of seven images and includes:

- five pairs of women's shoes of the glue method of fastening, decorated with details made using the leather embossing technique. Decorative details are presented as constructive elements of shoes, and removable. For attaching removable parts, various attachments to the bootleg were used: using a belt, carabiners, rings.

- seven sets of clothes of various designs.

- eight bags of various types and designs, decorated with the embossing technique. An airbrush was used to give the details a "patina" effect, aging color. The bags combine materials of different textures and composition (natural cattle leather, seal fur, slings, quilted fabric).

- hats and harnesses.

Materials used: seal fur, chrome tanned leather, pigskin.

The collection of footwear and accessories "The Future of the Past" is made in a modern interpretation of ethnic and military style using the method of hand embossing, weaving and airbrushing (Fig. 7). Table 2 shows the stage of performing the technique of hand embossing using a substrate and molds on the decorative part of the bootleg, performed according to scientific information material.

Table 2. Approbation of scientific research institute "The use of various materials and decorating techniques in the collections of footwear and accessories", authors Rykova, Polishchuk archive of the department of AMDTLP of the RSU named after Kosygin (fragment)

\begin{tabular}{ll}
\hline № & $\begin{array}{c}\text { Illustration of the operation of the } \\
\text { leather embossing technique (photo } \\
\text { from the archive of the Department } \\
\text { of Chemical Metallurgy of the RSU } \\
\text { named after Kosygin) }\end{array}$
\end{tabular}

The collection "Future of the Past" was awarded with diplomas of all-Russian and international design competitions and diplomas for preserving the traditions of national culture, dedication to folk art, and high professional skills. 


\section{Conclusion}

We have analyzed the methods of leather surface treatment: we have studied the history of the development of artistic leather processing, identified the main processing techniques, developed the collections using the techniques of painting with paints, intarsia, applique and embossing of leather.

The collection «Own Territory» was awarded the diploma of the 2nd place of the International Competition for Designers of Shoes and Accessories "Shoes-Style-2019" in the category "Shoes and Accessories". The collection «Future of the Past» was awarded with diplomas of all-Russian and international design competitions and diplomas for preserving the traditions of national culture, dedication to folk art, and high professional skills. Thus, we have proved that the use of techniques for working with leather is relevant and is one of the factors in the development of art education and can serve as the basis for modern design of shoes and accessories.

\section{References}

Acharya, A., Singh, S.K., Pereira, V., Singh, P. (2018). Big data, knowledge co-creation and decision making in fashion industry. International Journal of Information Management, 42(5), 90-101.

Almond, K. (2010). Insufficient allure: The luxurious art and cost of creative pattern cutting. International Journal of Fashion Design, Technology and Education, 3(1), 15-24.

Brito, P.Q., Soares, C., Almeida, S., Monte, A., Byvoet, M. (2015). Customer segmentation in a large database of an online customized fashion business. Robotics and Computer-Integrated Manufacturing, 36, 93-100.

D'Avolio, E., Bandinelli, R., Rinaldi, R. (2015). Improving new product development in the fashion industry through product lifecycle management: a descriptive analysis. International Journal of Fashion Design, Technology and Education, 8(2), 108-121.

Falko, L.Yu., Kravtsova, T.A., Lukasheva, I.A. (2018). The process of creating a fashion collection. Means of combining models in a collection. Retrieved from: https://abc.vvsu.ru/books/l_hud_kons/page0020.asp

Jacome, H., Glyn, S. (2016). Master Shoemakers: The Art and Soul of Bespoke Shoes. Artisan's Press (Publishing) Limited.

Lee, J.S., Jirousek, C. (2015). The development of design ideas in the early apparel design process: a pilot study. International Journal of Fashion Design, Technology and Education, 8(2), $151-161$.

Mochalina, D.R., Rykova, E.S., Fokina, A.A. (2018). Study of Pop Art Style for Creating a Collection of Shoes. Innovative Development of Light and Textile Industries (INTEX-2018): collection of materials of the International Scientific Student Conference, 88-92

Mochalina, D.R., Rykova, E.S., Fokina, A.A. (2019). Features of the techniques of artistic painting of leather. Innovative development of light and textile industries (INTEX-2019): collection of materials of the International Scientific Student Conference, 102-105.

Mondrian, P. Abstract fashion. Pete Mondrian. Retrieved from: эгоисты.pф/post/19

Paintings by Roy Lichtenstein. Retrieved from: https://allpainters.ru/

Polishchuk, O.A., Rykova, E.S. (2019). Decorative and applied arts in the modern fashion industry. Innovative development of light and textile industries: collection of materials of the International Scientific Student Conference, 197-200.

Pop art style in clothes. Retrieved from: https: https://tossy.ru/ 
Quinn, B. (2010). Textile Futures. Berg Publishers.

Rykova, E.S., Medvedeva, O.A. (2019). Analysis of the prospects for the development of collections of footwear and accessories made from alternative materials. Modern engineering problems in the production of consumer goods: a collection of scientific papers of the International Scientific and Technical Symposium "Modern Engineering Problems in the Production of Consumer Goods" of the International Kosygin Forum "Modern Tasks of Engineering Sciences", 182-186.

Vass, L., Monlar, M. (2017). Handmade Shoes for Men. H.F.Ullmann publishing. 